\title{
Modulation of olfactory bulb network activity by serotonin: synchronous inhibition of mitral cells mediated by spatially localized GABAergic microcircuits
}

\author{
Loren J. Schmidt and Ben W. Strowbridge \\ Department of Neurosciences, Case Western Reserve University School of Medicine, Cleveland, Ohio 44106, USA
}

\begin{abstract}
Although inhibition has often been proposed as a central mechanism for coordinating activity in the olfactory system, relatively little is known about how activation of different inhibitory local circuit pathways can generate coincident inhibition of principal cells. We used serotonin (5-HT) as a pharmacological tool to induce spiking in ensembles of mitral cells (MCs), a primary output neuron in the olfactory bulb, and recorded intracellularly from pairs of MCs to directly assay coincident inhibitory input. We find that 5-HT disynaptically depolarized granule cells (GCs) only slightly but robustly increased the frequency of inhibitory postsynaptic inhibitory currents in MCs. Serotonin also triggered more coincident IPSCs in pairs of nearby MCs than expected by chance, including in MCs with truncated apical dendrites that lack glomerular synapses. That serotonin-triggered coincident inhibition in the absence of elevated GC somatic firing rates suggested that synchronized MC inhibition arose from glutamate receptor-mediated depolarization of GC dendrites or other (non-GC) interneurons outside the glomerular layer. Tetanic stimulation of GCL afferents to GCs triggered robust GC spiking, coincident inhibition in pairs of MCs, and recruited large-amplitude IPSCs in MCs. Enhancing neurotransmission through NMDARs by lowering the external $\mathrm{Mg}^{2+}$ concentration also increased inhibitory tone onto MCs but failed to promote synchronized inhibition. These results demonstrate that coincident $\mathrm{MC}$ inhibition can occur through multiple circuit pathways and suggests that the functional coordination between different GABAergic synapses in individual GCs can be dynamically regulated.
\end{abstract}

Rhythmic sensory input to the olfactory bulb (OB), the secondorder brain region in the olfactory system, recruits complex inhibitory responses (Hamilton and Kauer 1989) that help shape spike patterns of mitral and tufted neurons during basal respiration and sniffing (Abraham et al. 2010). Divergent inhibitory input from granule cells (GCs), the most numerous interneuron subtype within the $\mathrm{OB}$, onto principal cells has been proposed to mediate spike synchronization among subpopulations of principal cells (Galán et al. 2006). However, the ability of GCs, and other bulbar interneurons, to generate coincident inhibition on groups of principal neurons has been studied directly (using paired intracellular recordings) only infrequently.

Coincident inhibitory responses onto mitral cells (MCs) synaptic input that could potentially synchronize firing patterns in output neurons by either resetting intrinsic membrane potential oscillations (Desmaisons et al. 1999) or triggering rebound activity (Desmaisons et al. 1999; Galán et al. 2006; Balu and Strowbridge 2007) — have only been reported in the literature infrequently, including directly following current steps to MCs (Isaacson and Strowbridge 1998) and in short-duration epochs following tetanic sensory afferent stimulation (Schoppa 2006a). Complicating the interpretation of responses to tetanic stimulation in a resonant brain region such as the OB (Rall and Shepherd 1968; Freeman 1975; Desmaisons et al. 1999; Galán et al. 2006) is the possibility that coincident spiking or synaptic activity following the stimulus might reflect the triggering stimulus rather than synchronization emerging de novo through the intrinsic properties of $\mathrm{OB}$ neurons or their synaptic connections.

Corresponding author: bens@case.edu

Article is online at http://www.learnmem.org/cgi/doi/10.1101/lm.035659.114.
In the present study, we find that the neuromodulator serotonin (5-HT) directly depolarizes MCs, increasing their spontaneous firing rates in rodent brain slices, while appearing to have little direct action on inhibitory GCs. We then used 5-HT to determine whether a gradual increase in spiking activity induced over a large population of principal cells promotes coincident inhibition in MCs. We find a selective increase in synchronized inhibitory input among nearby, but not distant, pairs of MCs with 5-HT. The ability of 5-HT to promote coincident inhibition required non-NMDAR-mediated excitation of GABAergic interneurons and was not mimicked by treatment with low $\mathrm{Mg}^{2+}$ extracellular solutions that directly enhanced dendrodendritic inhibition (DDI). These results demonstrate that AMPAR-triggered depolarization of $\mathrm{OB}$ interneurons can generate coincident inhibition in the absence of synchronized excitatory drive from MCs.

\section{Results}

Direct and indirect effects of serotonin in olfactory bulb neurons

Although coherent inhibitory inputs have been proposed to underlie spike synchrony in principal cells in the OB during sensory responses (Freeman 1972; Kashiwadani et al. 1999; Galán et al. 2006; Kay and Stopfer 2006), relatively few studies have

(C) 2014 Schmidt and Strowbridge This article is distributed exclusively by Cold Spring Harbor Laboratory Press for the first 12 months after the fullissue publication date (see http://learnmem.cshlp.org/site/misc/terms. xhtml). After 12 months, it is available under a Creative Commons License (Attribution-NonCommercial 4.0 International), as described at http:// creativecommons.org/licenses/by-nc/4.0/. 
directly assayed the inhibitory local circuits responsible for synchronous inhibition. Typically, electrical stimulation methods are employed to either activate glomerular inputs (Aungst et al. 2003; Schoppa 2006a,b) or focally activate circuits within the plexiform layers (Nakashima et al. 1978; Isaacson and Strowbridge 1998; Friedman and Strowbridge 2003). Utilizing in vitro OB slices, we used a pharmacological approach to activate large populations of MCs to probe circuits responsible for inhibitory synchronization.

In rat horizontal OB brain slices, bath application of $200 \mu \mathrm{M}$ 5 -HT significantly increased the frequency of spontaneous MC spiking assayed in cell-attached recordings (from $3.0 \pm 1$ to $20.3 \pm 4.7 \mathrm{~Hz}, P<0.001$, paired $t$-test, $n=8$ ) (Fig. $1 \mathrm{~A}-\mathrm{C}$ ). This depolarizing effect appeared to be mediated by postsynaptic 5-HT receptors on MCs as we found a similar increase in spontaneous spiking when 5 -HT was tested after ionotropic glutamate and $\mathrm{GABA}_{\mathrm{A}}$ receptors were blocked using an antagonist cocktail containing APV, NBQX, and gabazine (from $4.3 \pm 2.3$ to $20.6 \pm 5.9 \mathrm{~Hz}$, $P<0.01, n=11$ ) (Fig. 1C). Although previous studies have identified effects of 5 -HT on neurons within the glomerular layer (Hardy et al. 2005; Petzold et al. 2009), the depolarization of MCs we observed by 5 -HT persisted in dissected $\mathrm{OB}$ slices that lack a glomerular layer (Fig. 1D; as in Friedman and Strowbridge 2003), suggesting a direct effect on postsynaptic receptors located on the MC somata or dendritic processes contained in the external plexiform layer. These results are consistent with Hardy et al. (2005) who showed intracellular depolarization following activation of 5-HT2Rs on MCs, though the location of the postsynaptic 5-HT receptors was not determined in that study. In similar experiments recording from tufted cells (TCs, fast synaptic transmission blocked), we found heterogeneous results with three of four cell-attached recordings from TCs remaining silent before and after application of $200 \mu \mathrm{M} 5$-HT. The one spontaneously active TC increased its firing rate in 5-HT from 4.1 to $13.1 \mathrm{~Hz}$. One previous study (Liu et al. 2012) found direct depolarization of external TCs following activation of 5-HT2ARs. Given the possible heterogeneous effects of 5-HT on different subclasses of TCs, we focused the present study on 5-HT effects on MCs.

In cell-attached MC recordings, bath application of $200 \mu \mathrm{M}$ 5-HT elicited a rapid increase in spontaneous firing that subsided with a time constant of $44 \pm 9$ sec (Fig. 1E). We also found rapid onset kinetics in intracellular recordings under whole-cell current-clamp conditions (from $-69.2 \pm 0.9$ to $-58.7 \pm 2.2$ $\mathrm{mV}, \quad P<0.001, \quad n=9,200 \mu \mathrm{M} 5-\mathrm{HT}$ tested in APV, NBQX, and gabazine) (Fig. 1F). We took advantage of the rapid activation and desensitization kinetics following 5-HT applications in this study to determine the network consequences of brief (2-3 min) periods of induced spiking in populations of MCs.

We first asked if 5-HT also activated GABAergic GCs that form reciprocal dendrodendritic synapses with mitral and tufted cells (Fig. 2A,B; Rall et al. 1966; Isaacson and Strowbridge 1998). In 12 out of 14 GCs tested, $200 \mu \mathrm{M} 5$-HT depolarized the membrane potential. The mean membrane potential change following 5 -HT application in GCs was $3.4 \pm 0.7 \mathrm{mV}, n=14$. Serotonin also increased the apparent frequency of spontaneous EPSPs (Fig. 2C) though many of these synaptic events were of small amplitude and therefore difficult to analyze. Blocking ionotropic glutamate and $\mathrm{GABA}_{\mathrm{A}}$ receptors with $\mathrm{APV}, \mathrm{NBQX}$, and gabazine abolished most spontaneous synaptic activity in GCs and occluded the depolarizing effect of 5-HT (significantly different than the response to 5-HT without synaptic blockers, $P<0.002$, unpaired

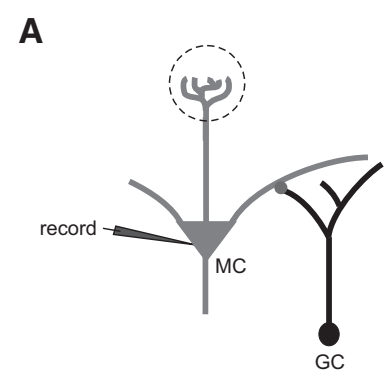

C

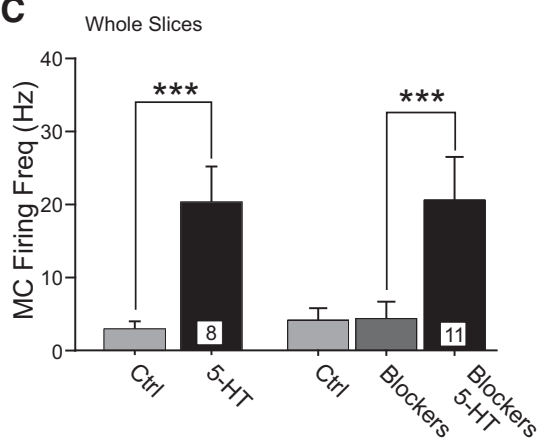

E

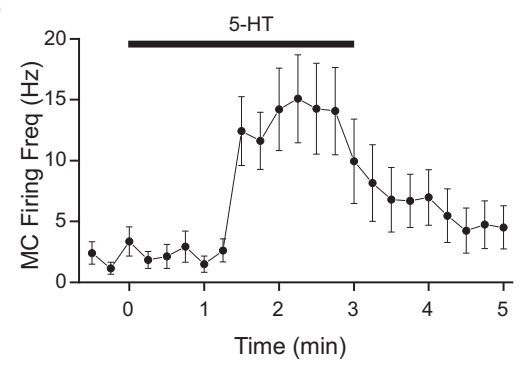

B
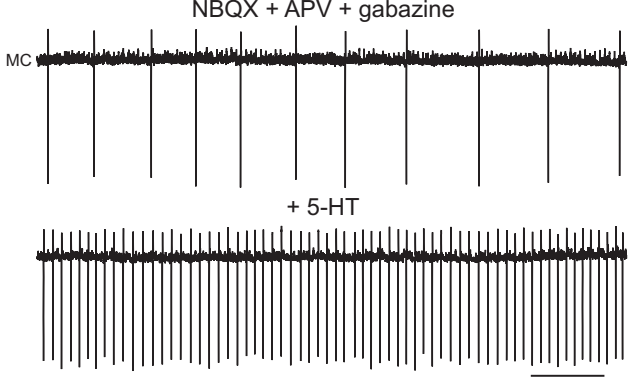

D

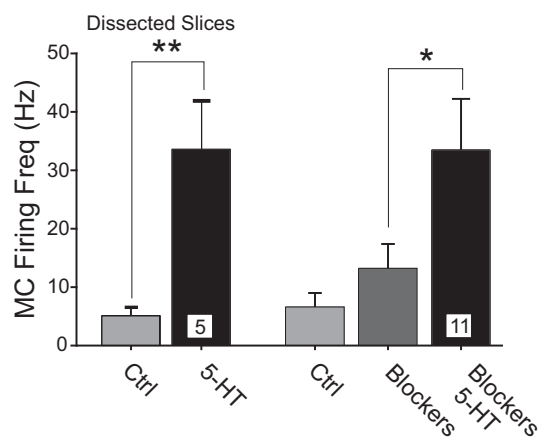

$\mathbf{F}$

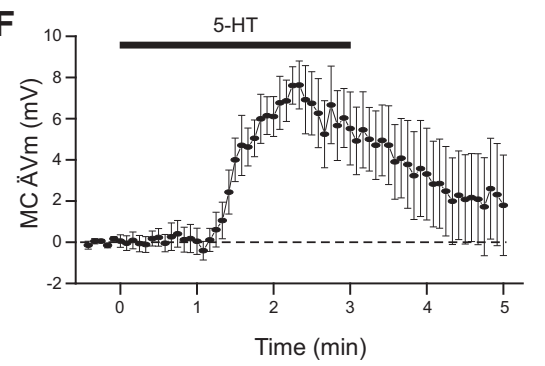

Figure 1. Serotonin directly depolarizes olfactory bulb mitral cells. (A) Cartoon of intracellular mitral cell (MC) recording configuration with synaptically connected granule cells (GCs). (B) Example cell-attached $M C$ recording with fast synaptic transmission blocked (5 $\mu \mathrm{M} N B Q X, 25 \mu \mathrm{M}$ D-APV, $10 \mu \mathrm{M}$ gabazine, GBZ). Bath application of serotonin (5-HT, $200 \mu \mathrm{M})$ increased the frequency of spontaneous MC action currents from $4.3 \pm 2.3$ to $20.6 \pm 5.9 \mathrm{~Hz}$. (C) Plot of increase in MC firing frequency following 5 -HT application in control conditions (left, $n=8$ experiments, $\left[{ }^{* * *}\right] P<0.001$, paired $t$-test) and when fast synaptic transmission was blocked with NBQX + APV + GBZ (Blockers) prior to 5-HT application (right, $n=11$ cell-attached recording experiments, $\left.{ }^{* * *}\right] P<0.001$, paired $t$-test). (D) Plot of increase in MC firing following 5-HT application in dissected OB slices without glomerular layers. Same conditions as indicated in $C .\left(^{* *}\right) P<0.02,\left(^{*}\right) P<0.05$, paired $t$-test. $(E)$ Plot of mean \pm SEM of MC firing rate in 14 cell-attached recordings in NBQX + APV + GBZ. (F) Time course of MC depolarization following bath application of $5-\mathrm{HT}(n=9 \mathrm{MCs}$ recorded in NBQX + APV + GBZ). 
A

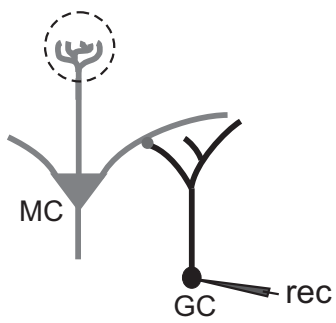

B
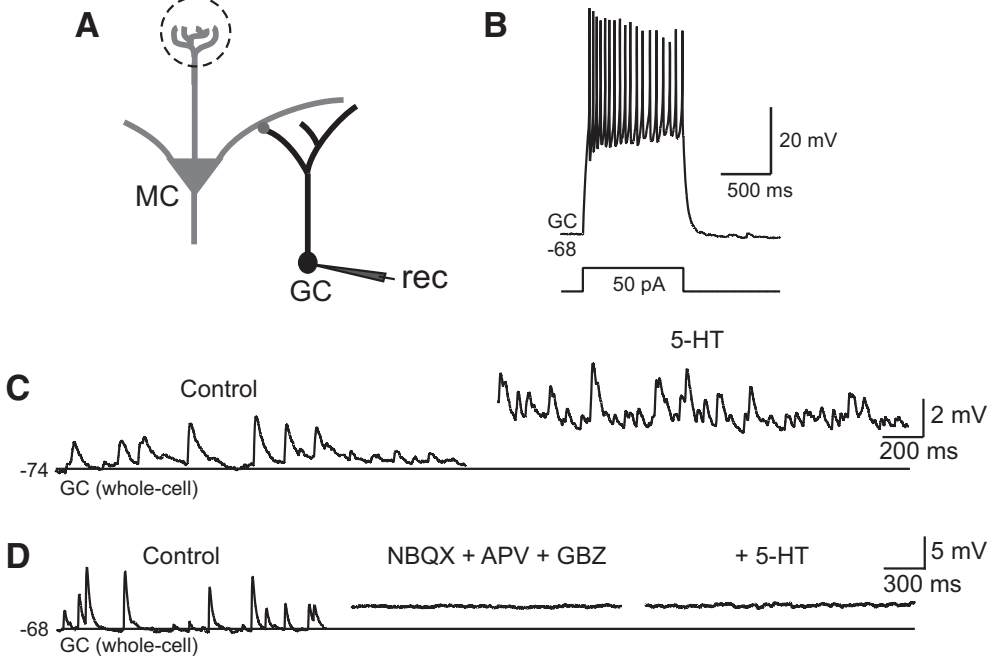

E
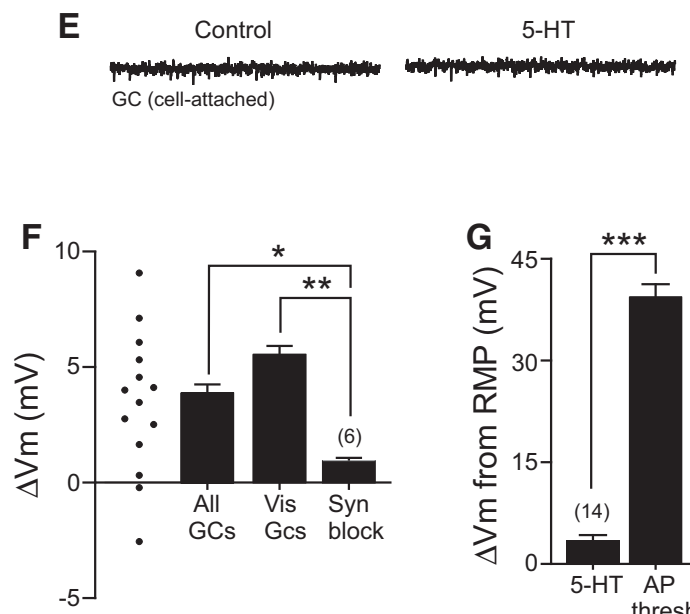

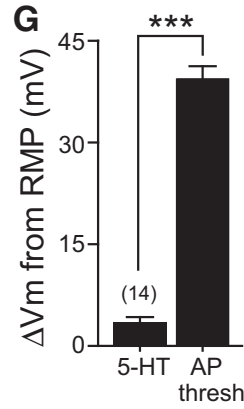

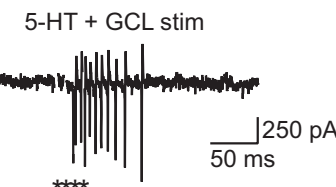

H

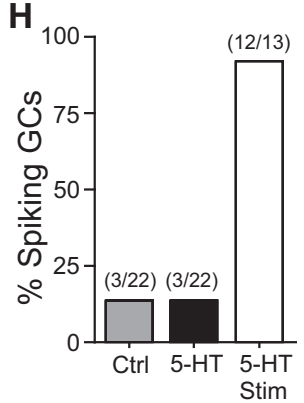

Figure 2. Indirect excitation of granule cells by serotonin. (A) Diagram of recording configuration. (B) Example granule cell (GC) response to a 50-pA depolarizing current step. (C) Example intracellular GC recording before and during 5-HT application. Horizontal line at $-74 \mathrm{mV}$ in both traces. (D) Blockade of fast synaptic responses with NBQX + APV + GBZ occludes depolarizing effect of 5-HT on GC. Horizontal line at $-68 \mathrm{mV}$ in all three traces. Mean membrane potential change in synaptic blocker cocktail was $0.4 \pm 0.7 \mathrm{mV}, n=6$, not significantly different from $0, P>0.05$. (E) Example cell-attached $\mathrm{GC}$ recording showing no spontaneous spikes before or after 5-HT application. Focal stimulation in the granule cell layer (GCL, asterisks) triggered a barrage of action currents in the same cell-attached recording (right trace). $(F)$ Plot of change in mean intracellular membrane potential in 14 GCs treated with $200 \mu \mathrm{M} 5-\mathrm{HT} ; \Delta V \mathrm{~m}$ from individual experiments indicated by symbols at left side. Serotonin triggered a similar membrane potential depolarization in subset of GCs with visualized and intact dendritic arbors within the external plexiform layer (Vis GCs, $n=4$ ). Granule cell 5-HT response was greatly attenuated when fast synaptic responses were blocked by NBQX + APV + GBZ (Syn Block, $n=6)$. $\left({ }^{* *}\right)$ $P<0.01,\left({ }^{*}\right) P<0.05$. (G) Plot of mean GC depolarization triggered by 5 -HT in control conditions $(n=14)$ relative to the membrane depolarization required to reach spike threshold from the same resting membrane potential $(n=14)$. $\left({ }^{* * *}\right) P<0.001$. $(H)$ Plot of the proportion of GCs recorded in the cell-attached configuration which discharged spontaneously in control conditions (Ctrl, gray bar, $3 / 22)$, following bath application of 5-HT (3/22), and following focal GCL stimulation in 5-HT (12/13).

$t$-test) (Fig. 2D-F). These results suggest that 5 -HT indirectly activated GCs, presumably primarily through the numerous dendrodendritic synapses formed between MCs and distal GC dendrites in the EPL. We also measured the sustained synaptic depolarization evoked by $200 \mu \mathrm{M} 5$-HT in four GCs visualized using live twophoton microscopy. All four visualized GCs had dendritic arbors that ramified within the EPL. Serotonin triggered a comparable steady-state depolarization in visualized GCs with intact dendritic arbors (Fig. 2F), suggesting that the relatively small amplitude of the synaptic depolarization recorded in GCs was not attributable to recordings from interneurons with truncated dendrites (and therefore few dendrodendritic synapses).

Consistent with the small amplitude of the steady-state depolarization 5-HTevoked in GCs and the relatively hyperpolarized resting potentials $(-67.7 \pm 1.1$ $\mathrm{mV}, n=14$ ) (Fig. 2G), we did not observe action potentials in whole-cell GC recordings within 5 min of 5 -HT application ( 0 out of 14 GCs tested). We confirmed the low incidence of 5-HT induced spiking in GCs by performing 22 cell-attached recordings under the same conditions where 5-HT reliably induced MC spiking (as in Fig. 1B,C). The same small fraction of GCs $(3 / 22)$ was spontaneously spiking before and after application of $200 \mu \mathrm{M} 5$-HT (Fig. 2E). Of the three out of 22 GCs that were spontaneously active before 5-HT, two increased their firing rates and one decreased firing following 5-HT treatment. We confirmed that we could detect spiking in cell-attached GC recordings by electrically stimulating in the granule cell layer following 5-HT application (Fig. 2E). Results from the GC cell-attached recording are summarized in Figure $2 \mathrm{H}$ and suggest that 5-HT-driven depolarization of $\mathrm{OB}$ principal cells synaptically excites GCs, resulting in a relatively small amplitude sustained somatic depolarization that remained subthreshold in nearly all GCs tested.

\section{Inhibitory feedback to mitral cells evoked by serotonin}

Despite only rarely triggering somatic spiking activity in GCs, 5-HT effectively increased the frequency of spontaneous inhibitory postsynaptic responses recorded in MCs (Fig. 3A1). The average frequency of spontaneous IPSCs recorded in MCs increased from $19.8 \pm 1.9$ to $47.0 \pm 3.6 \mathrm{~Hz}$ following 3-min treatment with $200 \mu \mathrm{M} 5$-HT (137.4\% increase, $P<$ $0.0001, n=61$; IPSCs recorded as inward currents as a consequence of reversed $\mathrm{Cl}^{-}$ gradient). The kinetics of 5-HT-evoked increase in inhibitory tone paralleled closely the time course of elevated MC spiking recorded in cell-attached recordings, including the rapid desensitization phase after $\sim 3$-min exposure to $200 \mu \mathrm{M}$ 5-HT (Fig. 3A,B). Blockage of $\mathrm{GABA}_{\mathrm{A}}$ receptors with gabazine $(\mathrm{GBZ}, 10 \mu \mathrm{M})$ occluded the effect of 5-HT on spontaneous synaptic currents in MCs ( $n=3 \mathrm{MCs})$ (Fig. 3A2).

Serotonin appeared to increase GABAergic inhibition of MCs via AMPA receptor-mediated depolarization of GCs. Blockade of NMDA receptors with D-APV $(25 \mu \mathrm{M})$ lowered the basal IPSC frequency recorded in MCs $(P<0.05, n=7$ cells) but failed to occlude the transient increase in IPSC frequency following 
$A_{1}$

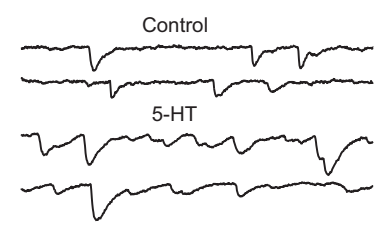

$\mathrm{A}_{2}$
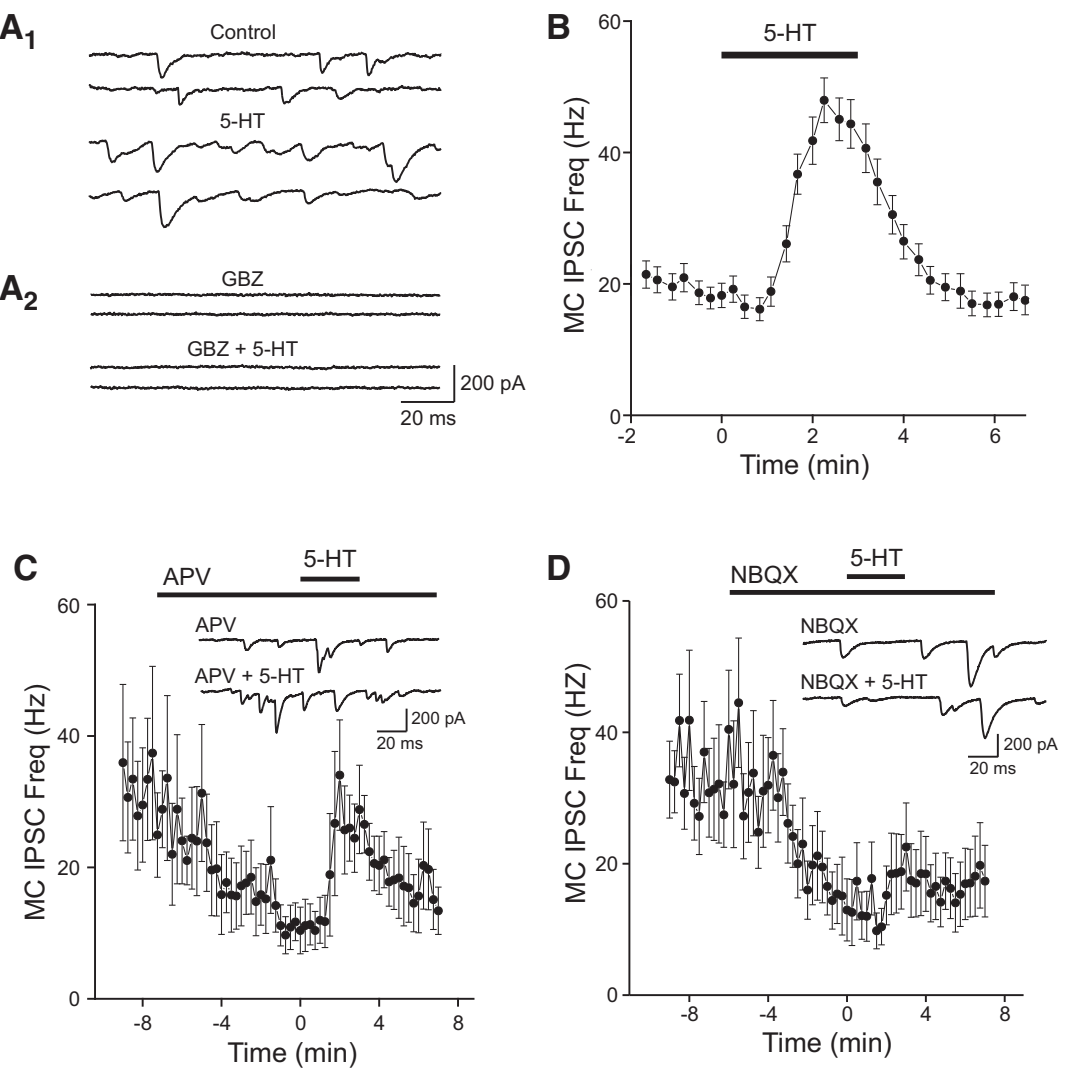

$\mathbf{E}$

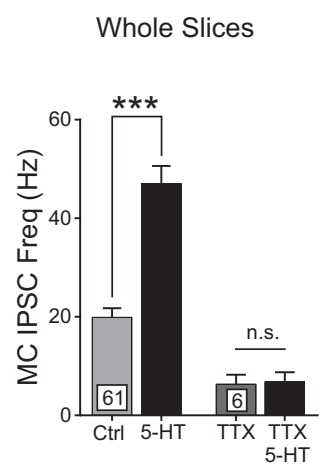

G

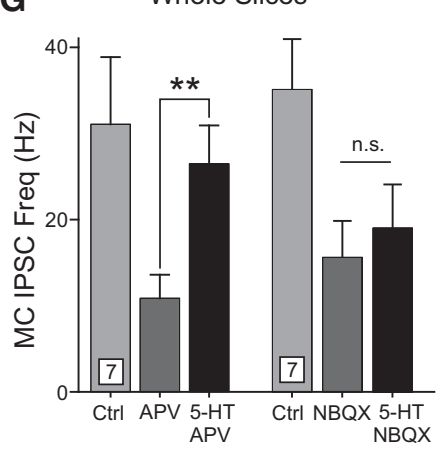

Figure 3. Serotonin triggers disynaptic inhibition onto mitral cells. (A1) Example MC voltage-clamp recordings illustrating the increase in spontaneous IPSC frequency during 5-HT application $\left(\mathrm{Cl}^{-}\right.$reversal potential reversed because of $\mathrm{CsCl}$ internal solution). (A2) Gabazine (GBZ, $10 \mu \mathrm{M}$ ) blocked spontaneous and 5-HT triggered inward currents. (B) Plot of the time course of the spontaneous IPSC frequency during 5-HT application. Each symbol represents mean \pm SEM from 61 MCs. (C) Plot of the increase in MC IPSC frequency with 5-HT after NMDARs were blocked with $25 \mu \mathrm{M}$ D-APV. Example traces in APV and APV + 5-HT shown in inset. (D) Plot of the effect of 5-HT on MC IPSC frequency after AMPARs were blocked with $5 \mu \mathrm{M}$ NBQX. Example traces shown in inset. (E) Summary of the increase in MC IPSC frequency with bath application of 5-HT in $61 \mathrm{MCs}$ recorded in OB brain slices in control conditions (left bars) and in $1 \mu \mathrm{M} \Pi \mathrm{TX}$ (right bars). (***) $P<0.001$, paired $t$-test, n.s., $P>0.05$. ( $F$ ) Plot of MC IPSC frequency increase with 5-HT in five experiments with dissected $\mathrm{OB}$ brain slices lacking glomerular layers. (***) $P<0.001$, paired $t$-test. $(G)$ Summary of the increase in MC IPSC frequency with 5 -HT in the presence of glutamate receptor antagonists. $\left.{ }^{* *}\right) P<0.01$, paired $t$-test, n.s., $P>0.05$.

5-HT (Fig. 3C). Blockade of AMPARs with NBQX (5 $\mu \mathrm{M})$ lowered the spontaneous IPSC frequency in MCs $(P<0.005, n=7$ cells $)$ and also prevented 5-HT from increasing inhibitory tone (Fig. 3D). Serotonin triggered a similar increase in spontaneous inhibitory tone (160\%) in dissected OB slices lacking glomerular layers $(P<0.0001)$ (Fig. 3E,F), suggesting that this response was independent of previously described effects of 5-HT on periglomerular circuits (Petzold et al. 2009). Bath applications of 5-HT had no effect on the rate of miniature IPSCs recorded in $1 \mu \mathrm{M}$ TTX, suggesting that the primary action of this transmitter was not related to mechanisms regulating GABA release from interneurons (Fig. 3E). The results summarized in Figure $3 \mathrm{E}-\mathrm{G}$ are consistent with the hypothesis that the primary effect of 5-HT in these experiments is on principal neurons and that the increase in inhibitory tone following bolus applications of 5-HT arises from AMPARmediated excitation of GABAergic interneurons outside the glomerular layer.

Serotonin appeared to depolarize MCs by binding to postsynaptic 5-HT2 receptors. The 5-HT2R antagonist cinanserin $(20 \mu \mathrm{M})$ (Peroutka and Snyder 1981) completely occluded the effect of bath application of $200 \mu \mathrm{M} 5$-HT (IPSC frequency $14.2 \pm 4.5 \mathrm{~Hz}$ before 5 -HT vs. $10.2 \pm 3.1 \mathrm{~Hz}$ in 5 -HT, $P>0.05$, paired $t$-test, $n=5)$. By contrast, the 5-HT1R antagonist pindolol $(25 \mu \mathrm{M})$ (Tricklebank et al. 1984) failed to block 5-HT-mediated increase in IPSC frequency $(12.1 \pm 3.1 \mathrm{~Hz}$ before 5-HT vs. $67.5 \pm 14 \mathrm{~Hz}$ in 5 -HT, $P<$ $0.001, n=5)$. Similarly, the $5-\mathrm{HT} 3 / 4 \mathrm{R}$ antagonist SDZ 205-557 (10 $\mu \mathrm{M})$ (Buchheit et al. 1991; Eglen et al. 1993) did not prevent the 5-HT-mediated increase in MC IPSC frequency $(9.4 \pm 2.9$ before 5 -HT vs. $31.7 \pm 8.2$ in 5 -HT, $P<$ $0.02, n=6)$. Also consistent with an action on 5-HT2Rs, we found the 5HT2AR-selective agonist TCB2 $(10 \mu \mathrm{M})$ (Fox et al. 2010) triggered a statistically significant increase in IPSC frequency $(16.5 \pm 2.8 \mathrm{~Hz}$ in control vs. $21.0 \pm 3.0$ $\mathrm{Hz}$ in TCB2, $P<0.02, n=5)$.

\section{Synchronous inhibition onto subpopulations of mitral cells}

In addition to increasing the overall frequency of spontaneous IPSCs, 5-HT triggered synchronous inhibition in pairs of closely spaced MCs but only infrequently in more distant pairs of MCs (Fig. 4A). Synchronous IPSCs following 5-HT treatment did not result from activity in inhibitory local circuits in the glomerular layer because we observed similar synchronous inhibitory responses in a near pair of MCs in which both cells had apical dendrites truncated before the glomerular layer (Fig. 4B). We used the clipped cross-intensity function (CIF) (Hahnloser 2007) to quantify the frequency of synchronous IPSCs within a given onset latency window (2-msec duration) and the frequency of coincident events expected by chance ("Shuf"). In the paired recording between visualized MCs without apical dendritic tufts, 5-HT triggered a statistically significant increase in CIF over the CIF 
expected by chance during 5-HT treatment $(P<0.0002)$ (Fig. 4C). The synchronous MC inhibition assayed by CIF only persisted for $\sim 1 \mathrm{~min}$, paralleling the rapid desensitization of the 5-HT-evoked increase in IPSC frequency (see Fig. 3B). We also found a statistically significant increase in MC IPSC CIF in a different visualized pair of MCs in which each neuron contacted a different glomerulus (70 $\mu \mathrm{m}$ between cell bodies, 0.22 IPSC CIF, $P<0.001$, not shown). Over a set of 13 paired recordings between nearby MCs (cell bodies separated by $<200 \mu \mathrm{m}$, mean separation $=83.2 \pm 13$ $\mu \mathrm{m}), 5$-HT reliably triggered more synchronous IPSCs than expected by chance (actual CIF was significantly larger than CIF computed following shuffling inter-IPSC intervals, $P<0.005$ ) (Fig. 4D). We also observed a smaller, but still statistically significant, increase in IPSC synchrony in eight pairs of MCs separated by between 200 and $1000 \mu \mathrm{m}$ and no increase in IPSC synchrony above chance in five MC pairs separated by $>1000 \mu \mathrm{m}$ (Fig. 4D). The lack of IPSC synchrony in distant pairs of MCs was not due to variation in effectiveness of 5-HT in driving inhibitory local circuits, since 5-HT elevated mean IPSC frequencies similarly in three paired recording configurations (Kruskal-Wallis ANOVA, $P>0.05)$ (Fig. 4E).

When plotted directly against MC separation (Fig. 4F), 5-HTdriven "excess" IPSC synchrony (actual CIF-expected CIF estimated by shuffling inter-event intervals) decreased sharply with distance; most paired recordings separated by $<150 \mu \mathrm{m}$ had excess IPSC synchrony. By contrast, few paired recordings separated by $>150 \mu \mathrm{m}$ had more IPSC synchrony than expected by chance (near 0 excess CIF). These results suggest that despite the long length of MC dendritic processes (100s of microns) (Shepherd et al. 2004), coordinated inhibition only reliably occurred in pairs of closely spaced MCs under our experimental conditions. We also observed a large variation in degree of inhibitory coupling even between pairs of nearby MCs, as illustrated by the range of excess CIF estimates shown in Figure 4F. Serotonin triggered a statistically significant, but transient, increase in excess IPSC CIF that was extinguished rapidly ( $\sim 1 \mathrm{~min}$ after the IPSC frequency was maximal) (Fig. 4G). Mitral cell excess IPSC CIF was not correlated with the mean IPSC frequency in that episode $\left(R^{2}=0.20, n=26\right.$ episodes from 13 MC paired recordings with $<200-\mu \mathrm{m}$ separation). Together, these results suggest that the spatial extent of inhibitory local circuits revealed by 5 -HT is largely restricted to pairs of MCs separated by $<150 \mu \mathrm{m}$ and is most prominent in pairs separated by $<80 \mu \mathrm{m}$.

Next, we tested whether other experimental treatments that increased the frequency of spontaneous IPSCs also promoted synchronous inhibition in nearby pairs of MCs. Reducing extracellular $\mathrm{Mg}^{2+}$ concentration eliminated the tonic blockade of NMDARs (Ascher and Nowak 1987) and enhanced GC-mediated reciprocal dendrodendritic inhibition (Isaacson and Strowbridge 1998; Schoppa et al. 1998; Chen et al. 2000). Treatment with $\mathrm{Mg}^{2+}$-free ACSF increased the frequency of spontaneous IPSCs in MCs $(P<0.005, n=8$ experiments) (Fig. $5 \mathrm{~A}-\mathrm{D})$. Despite the robust increase in inhibitory tone evoked by low $\mathrm{Mg}^{2+}$ ACSF, we observed no increase in frequency of synchronous IPSCs assayed through cross-correlation analysis in two example experiments (Fig. 5B) and when IPSC CIF was assayed in four experiments $(P>0.05)$ (Fig. 5D). Even when the CIF analysis was restricted to large-amplitude IPSCs ( $>200 \mathrm{pA})$, that might reflect GABA release events triggered by dendritic spikes in GCs, we did not observe increased IPSC synchronization in low $\mathrm{Mg}^{2+}$ ACSF $(P>$ 0.05 actual CIF vs. shuffled interval controls, paired $t$-test). These results demonstrate that the synchronous inhibition of MCs triggered by 5-HT was not simply a result of enhanced inhibitory tone. Enhancing excitatory synaptic drive onto interneurons using low $\mathrm{Mg}^{2+}$ ACSF elevated the frequency of spontaneous IPSCs, and also triggered many more large-amplitude IPSCs than
5-HT, without promoting synchronous IPSCs in nearby pairs of MCs. Figure 5E summarizes the effects of two different experimental manipulations that increased IPSC frequency (5-HT and low $\mathrm{Mg}^{2+}$ ACSF) on synchronous MC inhibition. Only 5-HT increased inhibitory tone and also promoted synchronous inhibition, an effect that was robust over a wide range of CIF analysis window durations from 0.5 to $10 \mathrm{msec}$. The excess CIF evoked by 5-HT increased as the analysis window was lengthened from 0.5 to $4 \mathrm{msec}$ and then was asymptotic, suggesting that the jitter associated with mechanisms underlying coincident inhibition of MCs was $<4 \mathrm{msec}$. This estimate includes the jitter associated with transmitter release at both inhibitory synapses and the temporal variance associated the processes that link the two release sites.

Finally, we asked if tetanic stimulation in the GCL (Fig. 6A,B) evoked synchronous inhibition in MCs. GCL stimulation often triggered spiking in GCs (e.g., spiking triggered in 12 of 13 cell-attached GC recordings) (Fig. 2E); the mean firing rate was $7.8 \mathrm{~Hz} \pm$ $2.2 \mathrm{~Hz}$ in five GCs that responded to GCL stimulation throughout the analysis window employed below (100-1100 msec following
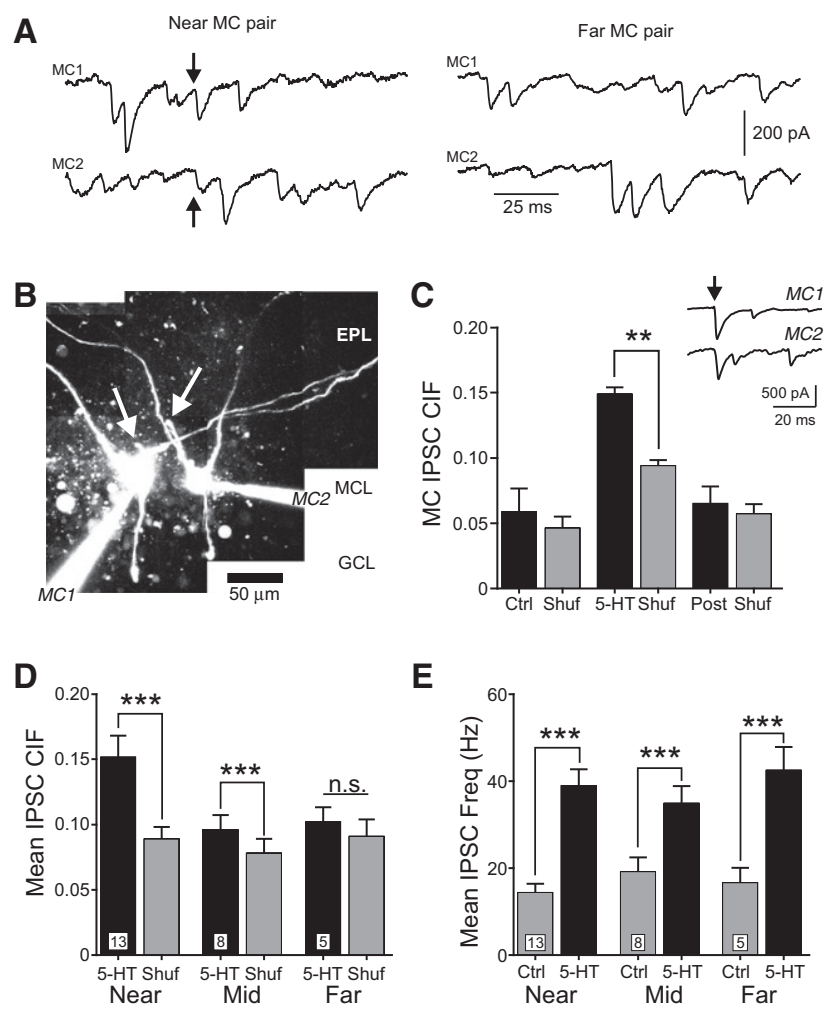

E
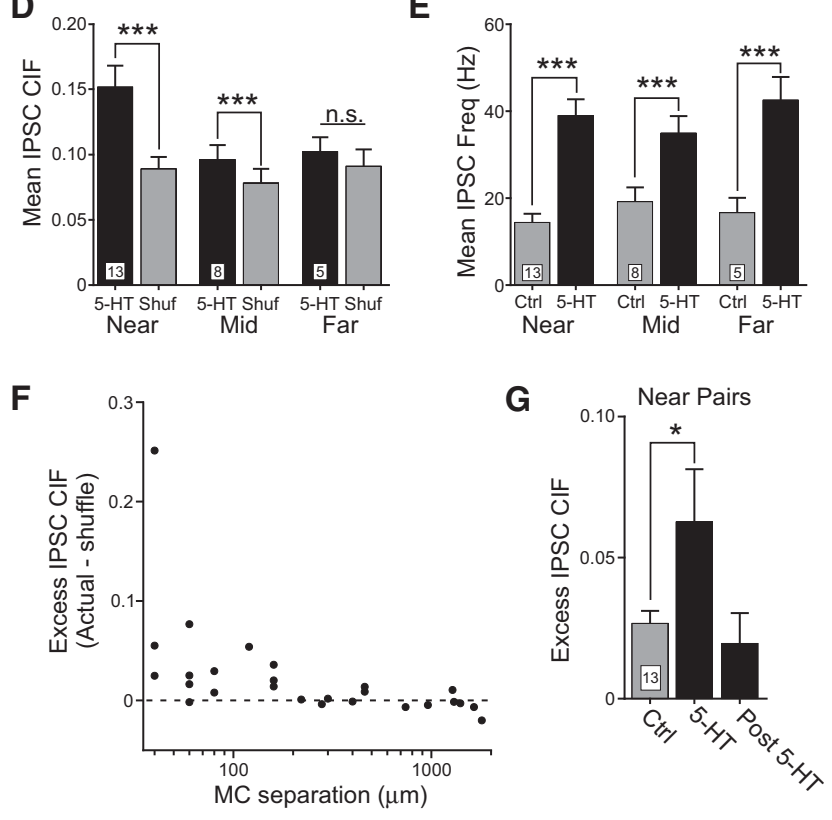

Figure 4. (Legend on next page) 
the last stimulus). We assayed coincident inhibition in pairs of MCs separated by $\sim 100 \mu \mathrm{m}$ (range $60-250 \mu \mathrm{m}$ ), a separation distance in which 5-HT only infrequently triggered synchronous inhibition (example traces presented in Fig. 6C). IPSC synchrony was significantly elevated in six of eight paired recordings following a tetanic stimulation (100-1100 msec following the last GCL stimulation, $P<0.05$ ); the group mean CIF also was significantly greater following GCL stimulation than CIF computed from shuffled IPSC times (160\% increase over bootstrap, $P<0.0005$ ) (Fig. $6 \mathrm{D})$. In the same set of eight paired recording experiments, 5-HT triggered only modest IPSC synchrony and a $15 \%$ increase in IPSC CIF $(P<0.05)$. When analyzed individually, only two of eight paired recordings had a significant elevation in IPSC CIF beyond the level expected by chance in 5-HT. Four of the six paired recordings that showed no increase in IPSC synchrony in 5-HT had statistically significant increases in IPSC CIF following tetanic stimulation. Excess IPSC CIF also was significantly increased over control conditions following GCL stimulation $(P<0.0002)$ but not following 5 -HT ( $P>0.05 ; n=8 \mathrm{MC}$ pairs) (Fig. $6 \mathrm{E})$. There was no statistically significant difference in mean IPSC frequency triggered by GCL stimulation and bath application of 5-HT $(P>$ 0.05) (Fig. 6F).

One advantage of assaying inhibitory synchrony using the CIF method is the ability to quantitatively determine the minimum test window duration required to capture coincident IPSCs. Simply expanding the duration of the sliding analysis window will always yield more detected coincident events. However, subtracting the bootstrap estimate of the frequency expected by chance for that window generated a metric (excess IPSC

Figure 4. Serotonin promotes synchronous inhibitory synaptic responses in pairs of nearby mitral cells. (A) Example intracellular responses in near pairs of MCs shown in left panel that include an IPSC recorded in both cells (arrows; IPSC onset latency differed by $0.8 \mathrm{msec}$ in the two MCs, $60-\mu \mathrm{m}$ spacing between mitral cell bodies). Example recordings in right panel from a distant MC pair with no synchronous IPSCS (740- $\mu \mathrm{m}$ spacing between MCs). (B) Reconstructions of dual MC recordings following intracellular labeling with $150 \mu \mathrm{M}$ Alexa594. Picture represents collage from multiple maximal Z-stack projections acquired using live two-photon imaging. Neither $\mathrm{MC}$ had an intact apical dendrite; arrows indicate primary dendritic processes directed toward the glomerular layer that were truncated at the surface of the brain slice. Calibration bar, $50 \mu \mathrm{m}$. (EPL) external plexiform layer, (MCL) mitral cell layer, (GCL) granule cell layer. (C) Inset, example dual voltage-clamp recordings from two MCs that received synchronous IPSCs during 5-HT treatment. Arrow indicates example synchronous IPSC recorded in both MCs (IPSC onset latency difference $=0.4 \mathrm{msec}$ in example shown). Plot of increase in clipped cross-intensity function (CIF) (2-msec analysis window) following 5-HT application. Gray bars represent results from bootstrap shuffles. 5-HT bar represents $140 \mathrm{sec}$ following start of 5-HT application; Post bar represents $200 \mathrm{sec}$ following 5-HT application. (**) $P<0.01$, paired Student's $t$-test, $n=4$ episodes in each condition. Mean \pm S.E.M. (D) Plot of MC IPSC synchrony estimated by clipped cross-intensity function (CIF) in near ( $<200-\mu \mathrm{m}$ separation between cell bodies), mid (200 to $1000-\mu \mathrm{m}$ separation), and distant ( $>1000-\mu \mathrm{m}$ separation) pairs of MCs. Gray columns represent average CIF computed from IPSC interval shuffles in each paired recording experiment. $\left(^{* * *}\right) \quad P<0.005$, paired $t$-test. Number of paired recording experiments analyzed indicated at base of each bar. (E) Plot of mean IPSC frequency in control (Ctrl) and 5-HT in paired $\mathrm{MC}$ recordings from the same three groups of experiments presented in $D$. (***) $P<0.005$, paired $t$-test. Mean IPSC frequencies in 5 -HT did not differ significantly between the three groups $(P>0.05$, Kruskal-Wallis ANOVA, same MC paired recordings analyzed in $D)$. $(F)$ Plot of excess IPSC CIF (Actual-mean from interval shuffles) vs. mitral cell body separation for 25 paired recording experiments. Dashed line represents no increase in frequency of coincident IPSCs over the frequency expected by chance (excess IPSC CIF $=0$ ). $(G)$ Summary of the increase in excess IPSC CIF following 5-HT in 13 MC pairs separated by $<200 \mu \mathrm{m}$; post bar indicates excess CIF at the same time window indicated in $C$. $\left({ }^{*}\right) P<0.05$, paired $t$-test.
CIF) that can be compared across different conditions. As shown in Figure 6G, this metric increased in parallel as the window duration was increased in both 5-HT and GCL stimulation conditions (open and filled symbols, respectively). Both curves were well fit by a model with each pair of near-coincident IPSCs originating from the same interneuron that had a synaptic release jitter of $2 \pm 0.5$ msec (mean \pm SD) (solid line in Fig. 6G; Kay and Wong 1987; Sabatini and Regehr 1999). More complex models of coincident inhibition arising from near-synchronous excitation of multiple interneurons included the jitter associated with EPSC responses on granule cells (1.1-2.3 msec) (Balu et al. 2007) and the jitter associated with EPSP-spike coupling (1.4-4.7 msec) (Schoppa 2006b; Rodriguez-Molina et al. 2007). Even using the EPSP and spike coupling mechanisms described in prior studies with relatively low jitter required significantly longer sliding analysis windows to capture coincident events than we found in our measurements (time constant significantly greater than either 5-HT or GCL stimulation conditions, $P<10^{-4}$ ) (dashed line in Fig. 6G). Using the estimate of the jitter associated with EPSPspike coupling in OB GCs (4.7 msec) (Schoppa 2006b) required even longer duration analysis windows (dotted line in Fig. 6G). These results suggest that following 5-HT and GCL stimulation, the coincident inhibition we observe in MCs likely arises from divergent output from individual interneurons.

Finally, we asked if we could differentiate the spontaneous IPSCs triggered by $5-\mathrm{HT}, 0 \mathrm{Mg}^{2+} \mathrm{ACSF}$, and GCL stimulation. As shown in the plots in Figure $6 \mathrm{H}, 5$-HT triggered IPSCs with a very similar distribution of amplitudes as control conditions $(P>$ $0.05, \mathrm{~K}-\mathrm{S}$ test). Reducing extracellular $\mathrm{Mg}^{2+}$ ions results in a uniform shift toward larger amplitude IPSCs (different from control, $P<10^{-8}$, K-S test) while GCL stimulation skewed the amplitude distribution toward large-amplitude IPSCs (different from control, $P<10^{-8}$; different from $0 \mathrm{Mg}^{2+}, P<10^{-8}$; K-S test). While the uniform enhancement of IPSC amplitude in $\mathrm{O} \mathrm{Mg}^{2+}$ ACSF could arise from multiple mechanisms, the selective increase in spontaneous large-amplitude IPSCs following GCL stimulation is consistent with the preferential recruitment of a population of IPSCs that was not strongly active under control conditions.

\section{Discussion}

We make three principal conclusions in this study. First, activation of large ensembles of MCs with 5-HT recruits inhibitory local circuits through a 5-HT2R- and AMPAR-dependent mechanism that forms divergent synapses on nearby but not distant pairs of principal neurons. Serotonin-driven inhibitory circuit activation functioned without frequent somatic spiking in GCs. Second, enhancement of dendrodendritic inhibition by removing extracellular $\mathrm{Mg}^{2+}$ ions increases inhibitory tone on MCs but fails to recruit coincident IPSCs on nearby pairs of MCs beyond the frequency expected by chance. Finally, tetanic stimulation of afferents in the GCL triggers robust synchronous inhibition of MCs, even in MC pairs where 5-HT triggered only modest coincident inhibition. These results suggest that different local circuits may regulate inhibition onto nearby MCs than clusters of principal cells that span multiple glomerular modules.

Although a variety of stimulation methods have been used to increase inhibitory tone onto MCs (Rall and Shepherd 1968; Nakashima et al. 1978; Jahr and Nicoll 1982), our results demonstrate that they can do so through very different local circuit pathways. Enhancing currents through NMDARs by applying $\mathrm{Mg}^{2+}$ free ACSF increased the frequency of spontaneous IPSCs recorded in MCs but failed to recruit coincident inhibition even in closely spaced pairs of principal cells. This treatment likely facilitated inhibition by directly activating reciprocal dendrodendritic 
A

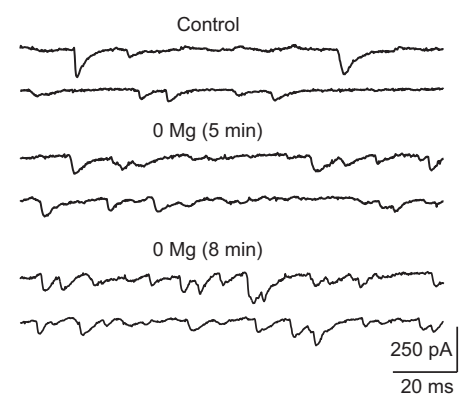

C

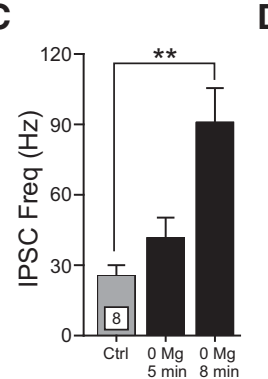

D

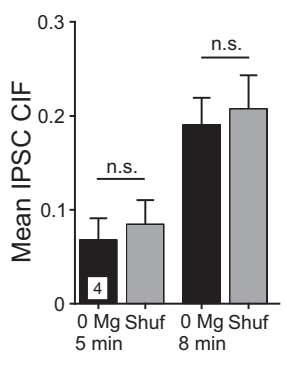

B

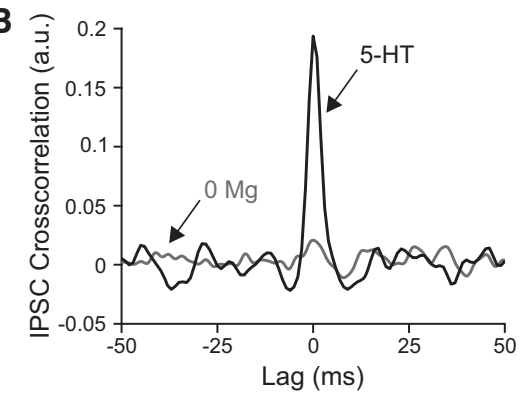

E

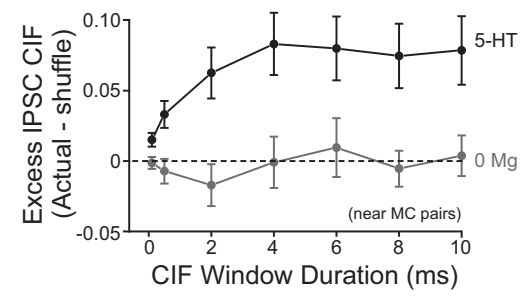

Figure 5. Low $\mathrm{Mg}^{2+}$ external solution increase spontaneous $\mathrm{MC}$ inhibition without promoting synchronous IPSCs in paired MC recordings. $(A)$ Example traces in one $M C$ under control conditions and at two time points following application of $0 \mathrm{Mg}^{2+}$ ACSF. (B) Example cross-correlograms computed from spontaneous IPSC onset times illustrating frequent coincident inhibitory inputs promoted by $5-\mathrm{HT}$ (black curve, peak at lag $=+0.2 \mathrm{msec}$ ) with no correlated inhibitory input triggered by 0 $\mathrm{Mg}^{2+}$ ACSF (gray curve, separate experiment). (C) Plot of spontaneous IPSC frequency in the four experimental conditions shown in $A$ for eight MCs. $(* *) P<0.005$. (D) Plot of MC IPSC CIF at two times following application of $0 \mathrm{Mg}^{2+}$ ACSF in four MC paired recordings $(<200-\mu \mathrm{m}$ cell body separation). Gray bars represent average CIF computed from 10,000 IPSC interval shuffles (Shuf). n.s., $P>0.05$. (E) Plot of the relationship between duration of synchronous IPSC detection window and excess CIF (Actual-expected from IPSC interval shuffles) in near MC paired recordings ( $<200-\mu \mathrm{m}$ cell body separation). Serotonin (5-HT, black symbols) increased IPSC CIF significantly above expected values for all coincident detection windows while $0 \mathrm{Mg}^{2+}$ (gray symbols) did not increase CIF beyond expected values at any coincidence window duration tested. Comparisons at all window durations tested were statistically significant in 5 -HT experiments $(P<0.01$, paired $t$-test).

synapses, an inhibitory pathway effectively driven by currents through NMDARs (Isaacson and Strowbridge 1998; Schoppa et al. 1998; Isaacson 2001). The absence of coincident inhibition (beyond the frequency expected by chance) suggests that the activation of granule cell dendrites during low $\mathrm{Mg}^{2+}$ treatment was localized and did not trigger synchronous GABA release at multiple dendrodendritic synapses at different positions along the dendritic arborization of individual GCs. The uniform shift toward larger amplitude IPSCs in low $\mathrm{Mg}^{2+}$ ACSF may reflect a higher probability of GABA release from dendrodendritic synapses onto MCs due to the larger $\mathrm{Ca}^{2+}$ influx under this experimental condition (Isaacson and Strowbridge 1998; Halabisky et al. 2000; Isaacson 2001).

Electrical stimulation of afferents in the GCL reliably triggered coincident inhibition in pairs of MCs and action currents in cell-attached recordings from GC somata, consistent with synchronous inhibition arising from spiking in GCs. Tetanic stimulation also skewed the MC IPSC amplitude distribution toward large-amplitude events, consistent with recruitment of an inhibitory circuit that was not active spontaneously in control conditions. Coincident IPSCs recorded in MCs had very low onset latency jitter, indicative of near-synchronous release of GABA from multiple synapses formed by the same presynaptic interneuron. Significantly greater jitter would be expected for synchronous inhibition arising from clusters of interneurons that spiked synchronously because they received coincident excitation. By assaying coincident inhibition starting $100 \mathrm{msec}$ after the last electrical shock, we sought to minimize IPSC synchronization mediated by synaptic inputs directly activated by the tetanic stimulus itself.

Activation of MCs with bath 5-HT triggered widespread spiking in MCs and also recruited coincident inhibition in groups of nearby principal cells, primarily in MC pairs separated by $<80$ $\mu \mathrm{m}$. The disynaptic depolarization we report in GCs following 5-HT is consistent with an increase in inhibitory tone in MCs mediated by GABA release at dendrodendritic synapses formed between granule and MC dendrites (Isaacson and Strowbridge 1998; Schoppa et al. 1998). However, coincident IPSCs could potentially arise from inhibitory cell types in the glomerular layer. Petzold et al. (2009) described an action of 5-HT on glomerular-layer inhibitory circuits mediated by 5 -HT2C receptors on periglomerular interneurons that could contribute to inhibitory tone in MCs despite the electrotonically distant location of these synaptic inputs. Presumably divergent connections formed by GABAergic periglomerular cells underlie coincident IPSCs recorded in the subclass of TCs located near the glomerular layer (external tufted cells) (Hayar et al. 2005). Several lines of evidence suggest that the modulation of inhibitory tone we observe in MCs is distinct from this effect in the glomerular layer. First, we observe similar increases in MC IPSC frequency in slices in which the glomerular layer was surgically removed. Second, we find a similar, statistically significant increase in IPSC synchronization in MCs with apical dendrites that do not arborize in the same glomerulus. Finally, modulation of periglomerular inhibitory circuits appears to rely primarily on 5-HT2C receptors while modulation of inhibitory tone can be evoked by the selective 5-HT2AR agonist TCB2. Petzold et al. (2009) found no effect on glomerular-layer circuit function when they tested the same 5-HT2AR agonist, a result that is consistent with the high density of 5-HT2ARs found primarily in the MC layer using immunohistochemistry (Hamada et al. 1998) and in situ hybridization (Pompeiano et al. 1994). While there is a consensus in the literature regarding 5-HT2CR expression in the glomerular layer (Pompeiano et al. 1994; Abramowski et al. 1995; Clemett et al. 2000; Petzold et al. 2009), several of these studies also found 5-HT2CR expression in deeper OB layers.

Unlike inhibitory responses triggered by tetanic GCL stimulation and low $\mathrm{Mg}^{2+}$ ACSF, the IPSC amplitude distribution was not significantly affected by 5 -HT. This result suggests that 5 -HT affected primarily inhibitory local circuits that were already active spontaneously (or triggered IPSCs that had similar amplitudes to spontaneous IPSCs). Surprisingly, the widespread excitatory synaptic drive elicited by 5-HT did not lead to frequent somatic spikes in GCs. Instead, intracellular recordings revealed these interneurons were typically only modestly depolarized by glutamatergic EPSPs during 5-HT and did not spike spontaneously. However, the low jitter we find associated with coincident MC inhibition driven by both 5-HT and GCL stimulation likely results 
A

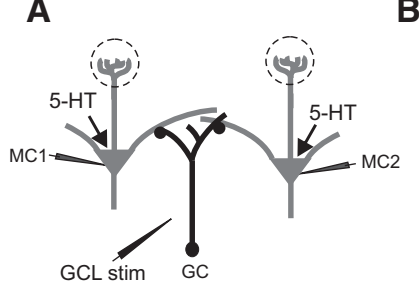

B

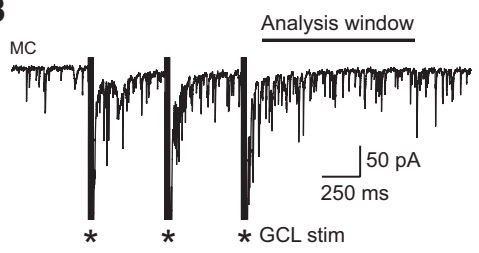

C
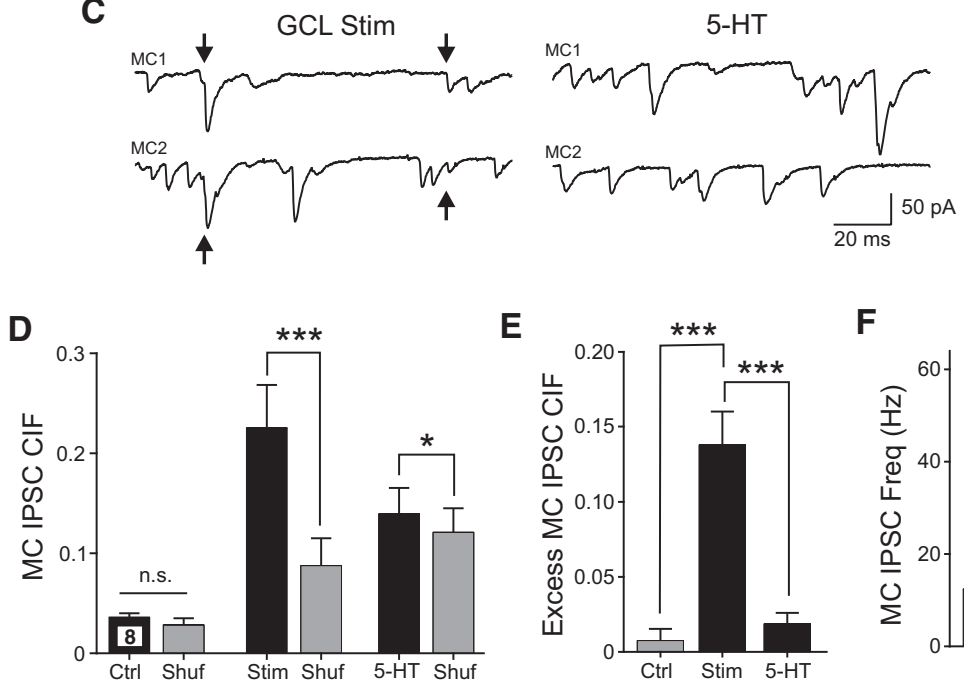

E

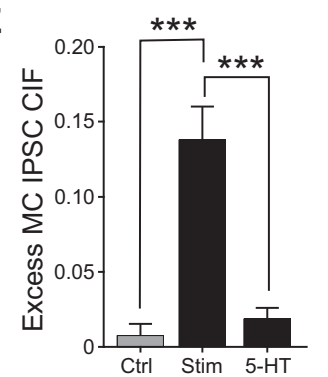

$\mathbf{F}$

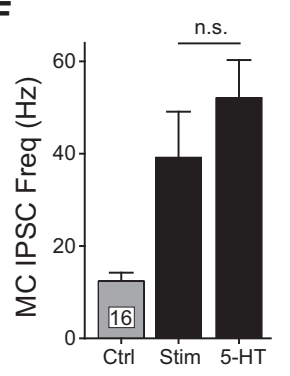

G

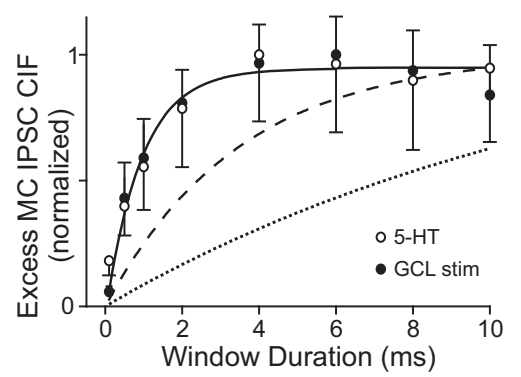

H

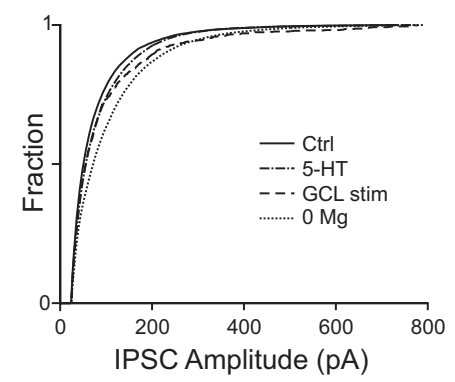

Figure 6. Synchronous $M C$ inhibition triggered by afferent stimulation. (A) Diagram of recording configuration. (B) Example recording of $M C$ response to tetanic stimulation in GCL (three bursts of four shocks at $100 \mathrm{~Hz}, 500-\mathrm{msec}$ inter-burst interval). (C) Enlargements of responses to GCL stimulation (left traces, arrows indicate IPSCs with onset latencies that differed by $<0.2 \mathrm{msec}$ ) in a paired MC recording with coincident inhibition. Bath application of 5-HT failed to evoke synchronous inhibition in the same pair of MCs (right traces). (D) Plot of the synchronous MC inhibition (IPSC CIF) present in control (Ctrl) conditions, following bath application of 5-HT, and following GCL stimulation (Stim). Estimates of IPSC synchrony expected by chance in each condition presented in gray columns (Shuf). (*) $P<0.05,\left(^{* * *}\right) P<0.005$, n.s., $P>0.05$, paired $t$-test. (E) Plot of excess CIF (Actual CIF-CIF expected by chance) in control conditions, 5-HT, and following GCL stimulation. (***) $P<$ 0.005 , paired t-test. $(F)$ Plot of increase in IPSC frequency in 5-HT and following GCL stimulation. Both conditions increased IPSC rate from control conditions $(P<0.005$, paired $t$-test). IPSC frequency did not differ significantly between $5-\mathrm{HT}$ and GCL stimulation conditions $(P>0.05$, n.s., paired $t$-test). (G) Plot of relationship between excess MC IPSC CIF and the duration of the sliding analysis window in both 5-HT (open symbols; mean \pm SEM, downward error bars) and following GCL stimulation (filled symbols; upward error bars). Solid line represents single divergent interneuron model with $2.0 \pm$ 0.5 -msec (mean $\pm \mathrm{SD}$ ) jitter associated with GABA release events. Dashed and dotted lines represent models of coincident IPSCs arising from excitatory synchronization of multiple interneurons. See Materials and Methods for details. $(H)$ Plot of the cumulative IPSC amplitude distributions for control conditions (solid line, $n=20$ cells), 5-HT (dash-dot line, $n=20$ ), $0 \mathrm{Mg}^{2+}$ ACSF (dotted line, $n=8$ ), and following GCL stimulation (dashed line, $n=16$ ).

from spiking in common presynaptic interneurons. Although the blockade of 5-HT-stimulated inhibition on MCs by AMPAR antagonists argues that the primary site of 5-HT action was not on interneurons, our results cannot exclude additional modulatory actions of metabotropic receptors that affect interneuron function.

There are at least two possible mechanisms that could explain 5-HT-stimulated synchronous inhibition in the absence of frequent GC somatic spiking. Serotonin-triggered coincident inhibition could arise from dendritic spikes in GCs that failed to trigger somatic action potentials or from spiking in an as-yetunidentified inhibitory local interneuron that targets MC cell bodies and/or proximal dendrites. Several studies have reported dendritically localized spiking in GCs, though often involving primarily low-threshold $\mathrm{Ca}^{2+}$ spikes (Egger et al. 2003, 2005). Spontaneous fast $\mathrm{Na}^{+}$-based dendritic spikes have been reported in frog GCs under basal (unstimulated) conditions (Zelles et al. 2006). If also present in mammals, spontaneous "D-spikes" could function to synchronize multiple dendrodendritic release sites in one GC, enabling coincident inhibition of nearby pairs of principal cells. The sensitivity of coincident inhibition in 5-HT to AMPAR antagonists suggests that these responses were likely recruited selectively by excitatory inputs with fast kinetics. Although we rarely observed spikelets in somatic intracellular recordings from GCs under basal or 5-HT-stimulated conditions that might correspond to dendritic D-spikes (Zelles et al. 2006), these events might not be easily detectable given the frequent synaptic inputs mammalian GCs normally receive in 5-HT.

Coincident inhibition of MCs also could arise from other (non-GC) interneurons that target MC somata or proximal dendrites, explaining the bias toward synchronous inhibition in near but not far MC pairs. At present, there is little evidence for axo-dendritic or axosomatic inhibition of MCs apart from periglomerular circuits. A wide variety of morphologically defined interneuron subtypes has been identified in the EPL and GCL that could potentially form axonal connections with MCs (Schneider and Macrides 1978; Pressler and Strowbridge 2006; Kosaka and Kosaka 2011; Pressler et al. 2013). Recent studies (Kato et al. 2013; Miyamichi et al. 2013) described a new class of parvalbumin (PV)-immunoreactive interneuron located in the external plexiform layer that could potentially mediate the synchronous IPSCs we observe in MCs in 5-HT. Alternatively, one or more subtypes of large "short-axon" interneurons in GCL, such as Blanes cells (Pressler and Strowbridge 2006) and Golgi cells (Pressler et al. 2013), may contact MCs in addition to GCs.

Although our experimental results cannot definitively determine whether coincident inhibition in 5-HT arises from dendritic 
D-spikes that couple multiple dendrodendritic GABA release sites within individual GCs or from divergent axonal input from another interneuron class, several lines of evidence are suggestive of the latter hypothesis. First, GCs are known to synapse along the length of MC secondary dendrites and, therefore, could potentially provide synchronous inhibition to widely separated pairs of MCs-which we did not observe. In principal, cable attenuation could explain the bias we found toward synchronous inhibition only in closely spaced MC pairs. However, using focal uncaging of GABA, Lowe (2002) recorded IPSCs originating from dendrodendritic synapses on lateral dendrites $\sim 200 \mu \mathrm{m}$ from the cell body that were often larger than spontaneously occurring IPSPs. Based on this prior uncaging study, we expected that divergent GC inputs should be detectable in our experimental conditions in MC pairs separated by $300-400 \mu \mathrm{m}$. The ability of GCL stimulation to recruit coincident inhibition in a set of paired MC recordings that showed little synchronous inhibition in 5-HT (Fig. 6D,E) also is suggestive of a role for two distinct inhibitory interneuron subtypes outside the glomerular layer. Inhibitory circuits recruited during 5-HT treatment typically linked clusters of MCs separated by $<\sim 100 \mu \mathrm{m}$ (likely only one or a few glomerular modules) while local circuits activated by GCL stimulation extended over larger clusters of MCs and included more glomerular modules. The significantly different IPSC amplitude distributions following 5-HT treatment and GCL stimulation also are suggestive of a role for non-GC interneurons.

Multiple investigators have hypothesized that the inhibitory local circuits formed between MCs and GCL interneurons operate on different spatial scales relative to the size of glomerular columns (Egger and Urban 2006, Balu et al. 2007). The smallest spatial scale is likely to be the reciprocal dendrodendritic synapse formed between MC and GC dendrites (Isaacson and Strowbridge 1998; Halabisky et al. 2000) which may function to gate AP propagation along the MC secondary dendrite (Chen et al. 2000). Unexpectedly, we found that widespread activation of these synapses following low $\mathrm{Mg}^{2+}$ ACSF triggered robust MC inhibition but little inhibitory synchrony, suggesting that dendrodendritic synapses may function to coordinate MCs on smaller spatial scales than assayed in this study. The other unexpected finding from this study was that activation of large ensembles of MCs did not generate inhibitory synchrony on the same spatial scale as MC dendritic processes, many of which span millimeters (Shepherd et al. 2004). Instead, we find coincident inhibition was restricted to a spatial scale similar to the size of a glomerular column. Given previous work demonstrating the ability of correlated inhibitory synaptic input to drive synchronous firing in MCs (Galán et al. 2006; Schoppa 2006a), a primary prediction from our study is that activation of inhibitory local circuits driven disynaptically by 5 -HT should promote to spike synchrony in MCs with same or neighboring glomerular modules. Unfortunately, it is not possible to directly test this prediction using the experimental paradigm used in this study because of the direct depolarizing effects of 5-HT on MCs. In principle, optogenetic methods that selectively depolarize the same interneuron population that was disynaptically excited by 5 -HT could test this hypothesis though additional studies will be required to identify the appropriate interneuron subclass.

\section{Materials and Methods}

\section{Slice preparation}

Horizontal OB slices (300 $\mu \mathrm{m}$ thick) were prepared from P14-P19 Sprague-Dawley rats, either sex, as previously described (Halabisky et al. 2000; Friedman and Strowbridge 2003; Balu et al.
2007). Slices were incubated in ACSF at $35^{\circ} \mathrm{C}$ for $30 \mathrm{~min}$ and then maintained at room temperature. All experiments were carried out in accordance with the guidelines approved by the Case Western Reserve University Animal Care and Use Committee.

\section{Electrophysiology}

All recordings were performed in a submerged recording chamber. Most recordings were performed at $34^{\circ} \mathrm{C}-35^{\circ} \mathrm{C}$; experiments visualizing GC dendritic arbors using two-photon imaging were performed at $30^{\circ} \mathrm{C}$. Slices were continuously perfused with an extracellular solution containing (in $\mathrm{mM}$ ): $124 \mathrm{NaCl}, 5 \mathrm{KCl}, 1.23$ $\mathrm{NaH}_{2} \mathrm{PO}_{4}, 1.2 \mathrm{MgSO}_{4}, 26 \mathrm{NaHCO}_{3}, 10$ dextrose, $2.5 \mathrm{CaCl}_{2}$, equilibrated with $95 \% \mathrm{O}_{2} / 5 \% \mathrm{CO}_{2}(\mathrm{pH} 7.3)$ at a flow rate of $1.5-2.0 \mathrm{~mL} /$ min. Whole-cell patch-clamp electrophysiological recordings were made using AxoPatch 1B or 1D amplifiers (Axon instruments) and borosilicate glass pipettes $(2-8 \mathrm{M} \Omega)$. All data were digitized at 5 or $10 \mathrm{kHz}$ by an ITC-18 computer interface (Instrutech) and a Windows 7 personal computer. Slices were imaged using IR/DIC optics on an upright fixed stage Zeiss Axioskop 1FS microscope and cells were identified based upon morphology, soma location within a slice, and intrinsic membrane properties. For current-clamp whole-cell and cell-attached recordings, the internal solution contained (in $\mathrm{mM}$ ): $140 \mathrm{~K}$ methylsulfate, $4 \mathrm{NaCl}, 10$ HEPES, 0.2 EGTA, 4 MgATP, $0.3 \mathrm{Na}_{3} \mathrm{GTP}, 10$ phosphocreatineTris. A CsCl-based internal solution was used for all MC voltageclamp recordings that reversed the $\mathrm{Cl}^{-}$gradient; it contained (in mM): $115 \mathrm{CsCl}, 4 \mathrm{NaCl}, 10$ HEPES, 1 EGTA, 25 TEA-OH, 5 QX-314, 4 MgATP, $0.3 \mathrm{Na}_{3}$ GTP, 10 phosphocreatine-Tris. All internal solutions were equilibrated to a pH of 7.3 and an osmolarity of $\sim 290 \mathrm{mmol} / \mathrm{kg}$. Serotonin phosphocreatine was prepared for use daily from powder (Sigma Aldrich). All other drugs were purchased from Tocris and were prepared in aliquots and frozen at $-20^{\circ} \mathrm{C}$ until use. Drugs were added to the bath by changing the source of external solution. Evoked responses were obtained using a constant current stimulus isolation unit (A-360, World Precision Instruments) and a monopolar tungsten electrode (FHC) placed in the GC layer. Neurons filled with Alexa594 through the patch pipette were imaged using a custom two-photon laser scanning system (Balu et al. 2007).

\section{OB slice microdissection}

Horizontal OB slices lacking a glomerular layer were prepared by first making two cuts perpendicular to the mitral cell layer (MCL) that extended through the entire slice, leaving a dissected slice $\sim 2 \mathrm{~mm}$ wide. The glomerular layer was then separated from the remaining tissue by making a third cut, parallel to the MCL, through the EPL (Friedman and Strowbridge 2003). All microdissection cuts were performed in a submerged recording chamber while visualizing the slice through a $5 \times$ objective. Dissected slices were allowed to recover for at least 20 min before attempting recordings. Dissected slices were stained with methylene blue dissolved in ACSF at the conclusion of each experiment to visualize the OB laminar structure. Only recordings from slices in which the glomerular layer was completely removed were analyzed.

\section{Data analysis}

Data analysis was performed with custom Matlab 2012b (Mathworks) scripts. Inhibitory and excitatory postsynaptic currents (IPSCs, EPSCs), and action potentials were automatically detected as previously described (Larimer and Strowbridge 2008). Briefly, traces were smoothed via a Savitsky-Golay filter and the instantaneous derivative was calculated. Events were defined by a cumulative $\mathrm{d} V / \mathrm{d} t$ or $\mathrm{d} I / \mathrm{d} t$ that exceeded a set threshold, and event times were defined by the first deviation toward threshold. Average frequencies of spikes or synaptic events were determined by taking the reciprocal of the average inter-event interval. All data are presented as mean \pm S.E.M. unless otherwise noted. The paired Student's $t$-test was used to determine statistical significance, unless otherwise specified. Autocorrelation and cross-correlation were 
performed by detecting events and convolving a 2-msec Gaussian kernel with the binary event times (Galán et al. 2006).

The clipped cross-intensity function (CIF) (Hahnloser 2007) was computed based on detected IPSC event times and used to determine whether the incidence of synchronous events was greater than expected by chance. To calculate the CIF for two response channels, we computed the total number of coincident (event onset latencies that differed by less than the synchronous window cutoff of 2-msec events, except for the analyses in Figures 5 and 6 that used varying duration windows) and divided by the total number of events on the channel with the fewest events. For example, one paired MC recording episode that contained 200 detected IPSCs in MC1 and 250 IPSCs in MC2, with 30 IPSCs that each occurred within $2 \mathrm{msec}$ on both channels, would have an IPSC CIF of $0.15(30 / 200)$. Two advantages of the CIF method, compared with correlation-based methods for detecting synchrony, are the ability to quantitatively define event synchrony over variable coincidence stringencies and the ability to directly compute estimates of synchrony expected by chance. Unless noted, all analyses were based on the average CIF computed over three control (pre 5-HT) and two consecutive 30-sec episodes acquired between 140 and $210 \mathrm{sec}$ after switchover to ACSF containing 5-HT. We computed CIF expected by chance for each episode by permuting the inter-event intervals contained in each channel; bootstrap CIF estimates were computed over $10^{4}$ to $10^{6}$ iterations. Bar plots labeled shuffled CIF reflect the mean of the bootstrap runs computed from each episode. "Excess" CIF was computed by subtracting the mean bootstrap CIF from the CIF computed from the actual event timing. Probability estimates obtained from individual episodes were computed from cumulative distribution functions based on the bootstrap estimates.

Estimates of excess IPSC CIF from interneurons that form divergent synaptic connections with MCs and clusters of interneurons synchronized by common excitatory input (Fig. 6G) were generated by a common template of 100 exactly synchronous events across two MCs and distributed with Poisson interevent intervals. For the divergent interneuron model (solid line in Fig. 6G), a separate IPSC releases jitter values drawn from a Gaussian distribution with a mean of 2.0 msec and a SD of 0.5 msec (Kay and Wong 1987; Sabatini and Regehr 1999) was added to each simulated MC channel. We constructed two models of nondivergent interneurons coupled by common excitatory inputs. The nondivergent model with lowest jitter (dashed line in Fig. 6G) was made by including glutamate release jitters of $1.1 \pm$ 0.2 msec (Balu et al. 2007) on each interneuron channel as well as the jitter associated with EPSP-spike coupling in neocortical neurons (1.4 $\pm 0.9 \mathrm{msec})$ (Rodriguez-Molina et al. 2007). Using the less reliable EPSP-spike coupling reported in OB GCs $(4.7 \pm$ $1.5 \mathrm{msec}$ ) (Schoppa 2006b) and the jitter associated with dendrodendritic EPSPs onto GCs $(2.3 \pm 3.2 \mathrm{msec})$ (Balu et al. 2007) required much longer sliding windows to capture synchronous IPSCs (dotted line in Fig. 6G).

\section{Acknowledgments}

We thank Roberto Galan and Robert Hyde for helpful discussions. We also thank Todd Pressler and Isaac Youngstrom for constructive comments on this manuscript. This study was supported by National Institute on Deafness and Other Communication Disorders grants R01-DC04285 to B.W.S. and F31-DC11213 to L.J.S.

\section{References}

Abraham NM, Egger V, Shimshek DR, Renden R, Fukunaga I, Sprengel R, Seeburg PH, Klugmann M, Margrie TW, Schaefer AT, et al. 2010. Synaptic inhibition in the olfactory bulb accelerates odor discrimination in mice. Neuron 65: 399-411.

Abramowski D, Rigo M, Duc D, Hoyer D, Staufenbiel M. 1995. Localization of the 5-hydroxytryptamine $2 \mathrm{C}$ receptor protein in human and rat brain using specific antisera. Neuropharmacology 34: 1635-1645.

Ascher P, Nowak L. 1987. Electrophysiological studies of NMDA receptors. Trends Neurosci 10: 284-288.
Aungst JL, Heyward PM, Puche AC, Karnup SV, Hayar A, Szabo G, Shipley MT. 2003. Centre-surround inhibition among olfactory bulb glomeruli. Nature 426: 623-629.

Balu R, Strowbridge BW. 2007. Opposing inward and outward conductances regulate rebound discharges in olfactory mitral cells. J Neurophysiol 97: 1959-1968.

Balu R, Pressler RT, Strowbridge BW. 2007. Multiple modes of synaptic excitation of olfactory bulb granule cells. J Neurosci 27: 5621-5632.

Buchheit KH, Gamse R, Pfannkuche HJ. 1991. SDZ 205-557, a selective antagonist at 5-HT4 receptors in the isolated guinea pig ileum. Eur I Pharmacol 200: $373-374$.

Chen WR, Xiong W, Shepherd GM. 2000. Analysis of relations between NMDA receptors and GABA release at olfactory bulb reciprocal synapses. Neuron 25: 625-633.

Clemett DA, Punhani T, Duxon MS, Blackburn TP, Fone KC. 2000. Immunohistochemical localisation of the 5-HT2C receptor protein in the rat CNS. Neuropharmacology 39: 123-132.

Desmaisons D, Vincent J-D, Lledo P-M. 1999. Control of action potential timing by intrinsic subthreshold oscillations in olfactory bulb output neurons. J Neurosci 19: 10727-10737.

Egger V, Urban NN. 2006. Dynamic connectivity in the mitral cell-granule cell microcircuit. Semin Cell Dev Biol 17: 424-432.

Egger V, Svoboda K, Mainen ZF. 2003. Mechanisms of lateral inhibition in the olfactory bulb: efficiency and modulation of spike-evoked calcium influx into granule cells. J Neurosci 23: 7551-7558.

Egger V, Svoboda K, Mainen ZF. 2005. Dendrodendritic synaptic signals in olfactory bulb granule cells: local spine boost and global low-threshold spike. J Neurosci 25: 3521-3530.

Eglen RM, Alvarez R, Johnson LG, Leung E, Wong EH. 1993. The action of SDZ 205,557 at 5-hydroxytryptamine (5-HT3 and 5-HT4) receptors. Br J Pharmacol 108: 376-382.

Fox MA, French HT, LaPorte JL, Blackler AR, Murphy DL. 2010. The serotonin 5-HT2A receptor agonist TCB-2: a behavioral and neurophysiological analysis. Psychopharmacology (Berl) 212: 13-23.

Freeman WJ. 1972. Depth recording of averaged evoked potential of olfactory bulb. J Neurophysiol 35: 780-796.

Freeman WJ. 1975. Mass action in the nervous system. Academic Press, New York.

Friedman D, Strowbridge BW. 2003. Both electrical and chemical synapses mediate fast network oscillations in the olfactory bulb. J Neurophysiol 89: $2601-2610$.

Galán RF, Fourcaud-Trocmé N, Ermentrout GB, Urban NN. 2006. Correlation-induced synchronization of oscillations in olfactory bulb neurons. J Neurosci 26: 3646-3655.

Hahnloser RHR. 2007. Cross-intensity functions and the estimate of spike-time jitter. Biol Cybern 96: 497-506.

Halabisky B, Friedman D, Radojicic M, Strowbridge BW. 2000. Calcium influx through NMDA receptors directly evokes GABA release in olfactory bulb granule cells. J Neurosci 20: $5124-5134$.

Hamada S, Senzaki K, Hamaguchi-Hamada K, Tabuchi K, Yamamoto H, Yamamoto T, Yoshikawa S, Okano H, Okado N. 1998. Localization of 5 -HT2A receptor in rat cerebral cortex and olfactory system revealed by immunohistochemistry using two antibodies raised in rabbit and chicken. Mol Brain Res 54: 199-211.

Hamilton KA, Kauer JS. 1989. Patterns of intracellular potentials in salamander mitral/tufted cells in response to odor stimulation. J Neurophysiol 62: 609-625.

Hardy A, Palouzier-Paulignan B, Duchamp A, Royet J-P, Duchamp-Viret P. 2005. 5-Hydroxytryptamine action in the rat olfactory bulb: in vitro electrophysiological patch-clamp recordings of juxtaglomerular and mitral cells. Neuroscience 131: 717-731.

Hayar A, Shipley MT, Ennis M. 2005. Olfactory bulb external tufted cells are synchronized by multiple intraglomerular mechanisms. J Neurosci 25: 8197-8208.

Isaacson JS. 2001. Mechanisms governing dendritic $\gamma$-aminobutyric acid (GABA) release in the rat olfactory bulb. Proc Natl Acad Sci 98: 337-342.

Isaacson JS, Strowbridge BW. 1998. Olfactory reciprocal synapses: dendritic signaling in the CNS. Neuron 20: 749-761.

Jahr CE, Nicoll RA. 1982. An intracellular analysis of dendrodendritic inhibition in the turtle in vitro olfactory bulb. J Physiol 326: 213-234.

Kashiwadani H, Sasaki YF, Uchida N, Mori K. 1999. Synchronized oscillatory discharges of mitral/tufted cells with different molecular receptive ranges in the rabbit olfactory bulb. J Neurophysiol 82: 1786-1792.

Kato HK, Gillet SN, Peters AJ, Isaacson JS, Komiyama T. 2013. Parvalbumin-expressing interneurons linearly control olfactory bulb output. Neuron 80: 1218-1231.

Kay LM, Stopfer M. 2006. Information processing in the olfactory systems of insects and vertebrates. Semin Cell Dev Biol 17: 433-442.

Kay AR, Wong RK. 1987. Calcium current activation kinetics in isolated pyramidal neurones of the CA1 region of the mature guinea-pig hippocampus. J Physiol 392: 603-616. 
Kosaka T, Kosaka K. 2011. "Interneurons" in the olfactory bulb revisited. Neurosci Res 69: 93-99.

Larimer P, Strowbridge BW. 2008. Nonrandom local circuits in the dentate gyrus. J Neurosci 28: 12212-12223.

Liu S, Aungst JL, Puche AC, Shipley MT. 2012. Serotonin modulates the population activity profile of olfactory bulb external tufted cells. J Neurophysiol 107: 473-483.

Lowe G. 2002. Inhibition of backpropagating action potentials in mitral cell secondary dendrites. J Neurophysiol 88: 64-85.

Miyamichi K, Shlomai-Fuchs Y, Shu M, Weissbourd BC, Luo L, Mizrahi A. 2013. Dissecting local circuits: parvalbumin interneurons underlie broad feedback control of olfactory bulb output. Neuron 80: $1232-1245$.

Nakashima M, Mori K, Takagi SF. 1978. Centrifugal influence on olfactory bulb activity in the rabbit. Brain Res 154: 301-306.

Peroutka SJ, Snyder SH. 1981. Two distinct serotonin receptors: regional variations in receptor binding in mammalian brain. Brain Res 208 339-347.

Petzold GC, Hagiwara A, Murthy VN. 2009. Serotonergic modulation of odor input to the mammalian olfactory bulb. Nat Neurosci 12: 784-791.

Pompeiano M, Palacios JM, Mengod G. 1994. Distribution of the serotonin 5-HT2 receptor family mRNAs: comparison between 5-HT2A and 5-HT2C receptors. Mol Brain Res 23: 163-178.

Pressler RT, Strowbridge BW. 2006. Blanes cells mediate persistent feedforward inhibition onto granule cells in the olfactory bulb. Neuron 49: 889-904.

Pressler RT, Rozman PA, Strowbridge BW. 2013. Voltage-dependent intrinsic bursting in olfactory bulb Golgi cells. Learn Mem 20: 459-466.

Rall W, Shepherd GM. 1968. Theoretical reconstruction of field potentials and dendrodendritic synaptic interactions in olfactory bulb. $J$ Neurophysiol 31: 884-915.
Rall W, Shepherd GM, Reese TS, Brightman MW. 1966. Dendrodendritic synaptic pathway for inhibition in the olfactory bulb. Exp Neurol 14: $44-56$.

Rodriguez-Molina VM, Aertsen A, Heck DH. 2007. Spike timing and reliability in cortical pyramidal neurons: effects of EPSC kinetics, input synchronization and background noise on spike timing. PLoS One 2: e319.

Sabatini BL, Regehr WG. 1999. Timing of synaptic transmission. Annu Rev Physiol 61: 521-542.

Schneider SP, Macrides F. 1978. Laminar distributions of interneurons in the main olfactory bulb of the adult hamster. Brain Res Bull 3: $73-82$.

Schoppa NE. 2006a. Synchronization of olfactory bulb mitral cells by precisely timed inhibitory inputs. Neuron 49: 271-283.

Schoppa NE. 2006b. AMPA/kainate receptors drive rapid output and precise synchrony in olfactory bulb granule cells. J Neurosci 26: 12996-13006.

Schoppa NE, Kinzie JM, Sahara Y, Segerson TP, Westbrook GL. 1998. Dendrodendritic inhibition in the olfactory bulb is driven by NMDA receptors. J Neurosci 18: 6790-6802.

Shepherd GM, Chen WR, Greer CA. 2004. Olfactory Bulb. In Synaptic organization of the brain, 5th ed. (ed. Shepherd GM), pp. 165-216. Oxford University Press, New York.

Tricklebank MD, Forler C, Fozard JR. 1984. The involvement of subtypes of the 5-HT1 receptor and of catecholaminergic systems in the behavioural response to 8-hydroxy-2-(di-N-propylamino) tetralin in the rat. Eur J Pharmacol 106: 271-282.

Zelles T, Boyd JD, Hardy AB, Delaney KR. 2006. Branch-specific $\mathrm{Ca}^{2+}$ influx from $\mathrm{Na}^{+}$-dependent dendritic spikes in olfactory granule cells. J Neurosci 26: 30-40.

Received May 12, 2014; accepted in revised form June 11, 2014. 


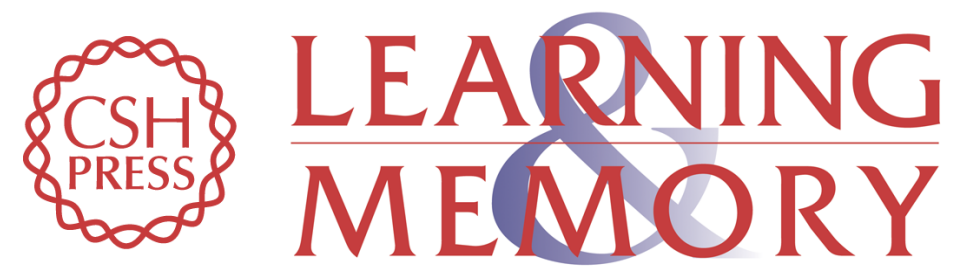

\section{Modulation of olfactory bulb network activity by serotonin: synchronous inhibition of mitral cells mediated by spatially localized GABAergic microcircuits}

Loren J. Schmidt and Ben W. Strowbridge

Learn. Mem. 2014, 21:

Access the most recent version at doi:10.1101//m.035659.114

References This article cites 52 articles, 13 of which can be accessed free at: http://learnmem.cshlp.org/content/21/8/406.full.html\#ref-list-1

Creative This article is distributed exclusively by Cold Spring Harbor Laboratory Press for the Commons first 12 months after the full-issue publication date (see

License http://learnmem.cshlp.org/site/misc/terms.xhtml). After 12 months, it is available under a Creative Commons License (Attribution-NonCommercial 4.0 International), as described at http://creativecommons.org/licenses/by-nc/4.0/.

Email Alerting Receive free email alerts when new articles cite this article - sign up in the box at the Service top right corner of the article or click here. 